In the figure, the real and imaginary components of $\mu_{a}$ for $\gamma \mathrm{Fe}_{2} \mathrm{O}_{3}$ are plotted, together with Hüttig's measurements ${ }^{1}$ on the solid oxide for wavelengths from 39 to $174 \mathrm{~cm}$.

Both oxides show a rapid decrease of $|\mu|$ with wave-length, and this is accompanied by a large magnetic absorption. The similarity of behaviour of the two oxides is almost certainly due to similarity of erystal structure, as suggested by Welo and Baudisch $^{2}$ from their work with static magnetic fields.

The measurements are being extended to solid samples of the two oxides, and to other ferromagnetic compounds, and it is hoped to widen the wave-length range with measurements at $1 \frac{1}{4} \mathrm{~cm} ., 15-60 \mathrm{~cm}$. and in static fields.

I wish to acknowledge my tenure of an I.C.I. Research Fellowship, and also the loan of apparatus by the Telecommunications Research Estáblishment.

Department of Natural Philosophy,

The University, Glasgow, W.2.

Oct. 11.

'Ministry of Supply, S.I.G.E.S.O. Report.

Welo and Baudisch, Phil. Mag., vi, 50, 399 (1925).

\section{Reflectivity of Nickel}

UsING a special vacuum furnace and a new multiplereflexion method to be described in detail elsewhere, I have determined the spectral reflectivity of nickel in the visible part of the spectrum over a range of $400^{\circ} \mathrm{C}$. A beam of light from a 100 -watt filament lamp was reflected four times at a nickel mirror, and compared with a standard beam from the same source, the intensity of the standard being reduced by means of a rotating sector until a match was obtained between the two for any given wave-length.

It was found that no discontinuity occurred at the Curie point. Following a theory of Gerlach's ${ }^{1}$ and an investigation on the emissivity of nickel in the infra-red by Löwe ${ }^{2}$, this was only to be expected: such a discontinuity does not occur for wave-lengths less than $4 \cdot 5 \mu$.

The temperature coefficient of reflectivity was found to be positive and varied from $0.85 \times 10^{-4}$ in the red to $1.6 \times 10^{-4}$ in the blue. This is in good agreement with Reid's ${ }^{3}$ value of $6 \cdot 6 \times 10^{-5}$ for $0.8 \mu$, and 0 at $2 \cdot 15 \mu$. It is well known that in the infra-red the temperature coefficient of reflectivity is negative for all metals. In fact, for wave-lengths greater than $10 \mu$, this coefficient is determined by the temperature coefficient of the electrical conductivity, the relation between reflectivity and conductivity $\sigma$ being

$$
R=1-2 \mathcal{V}_{\bar{\sigma}}^{\bar{\nu}}
$$

It is evident that for a certain wave-length the reflectivity coefficient must be zero. Attention was first directed to this phenomenon by Price ${ }^{4}$, but no explanation was advanced.

It is also known that the above equation breaks down as the visible part of the spectrum is approached from the infra-red, and Mott and Jones ${ }^{5}$ and Seitz ${ }^{6}$ believe that a surface layer of very great resistivity is responsible. The above findings throw some light on this hypothesis. If a surface layer caused the reduction in reflectivity which is found, then it might also be expected that the absolute value of the temperature coefficient would be reduced, since work on thin films has shown repeatedly that, as the film under test is made thinner, its conductivity and the temperature coefficient of the latter are reduced. Yet this does not explain the appearance of a positive temperature coefficient. In a few isolated cases very thin films (other than bismuth) have shown a positive temperature coefficient of conductivity. These results have generally been dismissed as due to a faulty technique in the preparation of the films, ete. Such objections, however, cannot be raised in connexion with solid metal mirrors the thickness of which is 0.2 in. In the case of reflectivity, two factors enter the picture : first the absorption coefficient $(n k)$ and secondly, the dielectric constant $(\varepsilon)$, where $n$ is the ordinary refractive index, and $k$ the extinction coefficient. Then, by Maxwell's equa'ions

$$
n k=\frac{\sigma}{\nu} \text { and } n^{2}-k^{2}=\varepsilon \text {, }
$$

$\nu$ being the frequency of light. The explanation advanced for the positive temperature coefficient of reflectivity is that, as the wave-length of light is reduced, the effect of the bound electrons becomes more marked, and thus the dielectric constant more prominent. To account for the positive temperature coefficient of reflectivity it is assumed that the part of the temperature coefficient of reflectivity to which the dielectric portions contribute is positive : this is a fair assumption since the dielectric constant of metals is often negative; if this constant is to have a meaning similar to that for insulators, its temperature coefficient also must be negative. Hence $\frac{-d(-\varepsilon)}{d T}$ is positive. Where the positive temperature coefficient of reflectivity (as conditioned by the dielectric) is equal to the negative coefficient (resulting from the free electrons or the conductivity), the point is obtained at which the temperature coefficient of reflectivity as determined by intensity measurements is zero.

To test the above hypothesis it is necessary to perform catoptric measurements so as to obtain the temperature variation of $\varepsilon$. A new sensitive method has been devised to this end, and experiments are in progress further to elucidate this problem of reflexion.

The above investigation was carried out for the Pyrometry Sub-Committee of the British Iron and Steel Research Association, which has kindly given permission for this communication to be published.

South-West Essex Technical College, ROBERT WEIL London, E.17. Oct. 9.

${ }^{1}$ Gerlach, Ann. Phys., 25, 209 (1936).

${ }^{2}$ Löwe, Ann. Phys., 25, 212 (1936).

${ }^{3}$ Reid, Phys. Rev., 60, 161 (1941).

${ }^{4}$ Price, J. Iron and Steel Inst., Paper No. 7 (1943). Nature, 157, 765 (1946).

"Mott and Jones "Properties of Metals and Alloys", Chap. 3, p. 120.

"Seitz, "Modern Theory of Solids"' (McGraw-Hill Book Co.), Chap. 17, p. 642 .

\section{The Ethoxyfluorsilanes}

Two compounds of this series, $\left(\mathrm{C}_{2} \mathrm{H}_{5} \mathrm{O}\right)_{2} \mathrm{SiF}_{2}$ and $\left(\mathrm{C}_{2} \mathrm{H}_{5} \mathrm{O}\right)_{3} \mathrm{SiF}$, were recently described by Peppard, Brown and Johnson'. I wish to point out that I had previously prepared and characterized ${ }^{2}$ the three compounds $\left(\mathrm{C}_{2} \mathrm{H}_{5} \mathrm{O}\right) \mathrm{SiF}_{3}, \quad\left(\mathrm{C}_{2} \mathrm{H}_{5} \mathrm{O}\right)_{2} \mathrm{SiF}_{2}$ and $\left(\mathrm{C}_{2} \mathrm{H}_{5} \mathrm{O}\right)_{3} \mathrm{SiF}$. The publication of this work has been prevented by war conditions; but a paper is now in preparation.

The monoethoxy compound is a colourless gas, boiling at about $-7^{\circ}$. It is unstable at room tem- 